\title{
Análise de conteúdo em termos de Bardin aplicada à comunicação corporativa sob o signo de uma abordagem teórico-empírica
}

\section{Content analysis in terms of Bardin applied to corporate communications under the sign of a theoretical and empirical approach}

\author{
Marconi de Allbuquereque Urquiza* \\ Denilson Bezerra Marques ${ }^{* *}$
}

\begin{abstract}
RESUMO: Objetivo deste artigo é apresentar a análise de conteúdo sob a metodologia desenvolvida por Bardin (2010) em duas partes, uma teórica e a outra empírica. Sendo que a primeira parte se estuda o método de pesquisa por viés teórico e a segunda parte estuda o uso do método de forma empírica na análise da comunicação corporativa de uma instituição financeira empregando todas as fases do método. 0 referencial teórico fundamental em termos base de conhecimento teórico para a metodologia foi a obra de Bardin (2010), em termos do desenvolvimento da parte empírica se utilizou Bedani (2008), com a tese de doutoramento que instruiu a análise do corpus quanto ao perfil corporativo, também o livro de Pagès (2008) quanto ao poder de influência das organizações e a análise da pesquisa no uso da pesquisa propriamente dita. A aplicação da metodologia análise de conteúdo resultou na identificação de cinco categorias extraídas do conjunto de dezenove mensagens emitidas entre 2011 e 2013 que formaram o corpus da comunicação corporativa estudada. Duas conclusões fundamentais são apresentadas, a primeira é que este método de pesquisa tem alta complexidade para ser implementado. A segunda conclusão fundamental diz respeito a grande confiabilidade dos seus resultados se 0 método for bem aplicado.
\end{abstract}

PALAVRAS-ChAVe: Análise de conteúdo. Comunicação corporativa. Pesquisa empírica.

\footnotetext{
- Mestre pelo Curso de Mestrado Profissional em Gestão Pública (MGP), Universidade Federal de Pernambuco - UFPE, E-mail: marconiurquiza19@gmail.com.

** Professor Doutor do Curso de Mestrado Profissional em Gestão Pública (MGP), Universidade Federal de Pernambuco - UFPE, E-mail: marquesdb@gmail.com.
} 
ABSTRACT: The objective of this article is to present the content analysis under the methodology developed by Bardin (2010), in two parts: one theoretical, and the other one empirical. In the first part we study the research method by the theoretical bias, and, in the second part, the use of the method on an empirical way, applying all its steps to analyze the corporative communication of a financial institution. The theoretical framework used to support the methodology was Bardin (2010). In terms of the development of the empirical part, Bedani (2008) was used as reference with his doctoral thesis which instructed the analysis of the corpus as far as the corporate profile. Pagès (2008) book was also used about the organizational influence power and analysis of research into the use of the research itself. The application of content analysis methodology resulted in the identification of five categories extracted from the set of nineteen messages, sent between 2011 and 2013, that formed the studied corpus of corporate communication. Two key findings are presented, the first one is that this method of research is highly complex to implement, and the second one concerns the great reliability of the results if the method is properly implemented.

KEYWORDS: Content analysis. Corporative communication. Empirical research.

\section{Introdução}

Este artigo se propõe trazer uma síntese, em termos teóricos e empíricos, da metodologia de pesquisa de comunicação Análise de Conteúdo desenvolvida por Bardin (2010), que tem um caráter essencialmente qualitativo, embora possa se utilizar de parâmetros estatísticos para apoiar as interpretações dos fenômenos da comunicação.

Inicialmente ocorre o desenvolvimento da parte teórica, com a discrição de todas as etapas do método, com um maior enfoque para a etapa de categorização, por ser a mais complexa desta metodologia. Também na etapa teórica, quatros-síntese foram construídos para ampliar a compreensão do leitor.

No início da parte empírica é apresentado o contexto que desencadeou a pesquisa que embasa este do artigo. Nesta etapa, além da contextualização, se trouxe o modo como se realizou a pesquisa e de que maneira foram utilizados os achados da comunicação empresarial de uma instituição financeira. As fases essencialmente práticas estão escritas na ordem proposta por Bardin (2010), desde a organização da análise ao trabalho com o material colhido à 
apresentação dos resultados.

Para o caso deste artigo, a pesquisa se desenvolveu com um corpus de dezenove mensagens corporativas coletadas entre junho de 2011 e dezembro de 2013, quase a totalidade foi emitida pelo Nível Gerencial Estratégico da instituição financeira.

Para ilustrar e apoiar o desenvolvimento do texto, outros recursos foram incorporados: quadros-síntese e figuras, construídos a partir da base empírica da pesquisa relatada.

Dando suporte à demonstração do desenvolvimento prático exposto neste artigo, foi incorporado um quadro-resumo da análise de conteúdo da categoria $A$ ideologia do resultado sustentável, há também uma análise simplificada junto da demonstração dos resultados decorrentes da exploração do corpus, inclusive com a utilização de figura, na qual se demonstra o percurso da pesquisa empírica.

Por fim, apresenta a conclusão que a metodologia é eficaz para a pesquisa de comunicação, mas que tem complexidade no seu desenvolvimento, em especial na categorização do material de pesquisa, uma etapa essencial para seu desenvolvimento.

\section{Análise de conteúdo em termos teóricos}

O método de pesquisa Análise de Conteúdo estudado neste artigo se baseou no trabalho de Bardin (2010, p. 280) e tem as seguintes fases para a sua condução: a) organização da análise; b) codificação; c) categorização; d) tratamento dos resultados, inferência e a interpretação dos resultados.

A fase organização da análise se subdivide em pré-análise, exploração do material, tratamento dos resultados em bruto e interpretação desses resultados.

Sendo a pré-análise a primeira etapa da organização da análise é por meio dela que o pesquisador começa a organizar o material para que se torne útil a pesquisa. Nesta fase, o analista deve sistematizar as ideias iniciais em 
cinco etapas. (BARDIN, 2010).

Na primeira das etapas da pré-análise, o pesquisador deve fazer a leitura flutuante, que implica em conhecer inicialmente o material e criar familiaridade com ele.

A segunda tarefa na pré-análise é a escolha dos documentos, após o pesquisador ter feito uma leitura flutuante ampla, realiza, em seguida, a escolha dos documentos que comporão o corpus da análise de conteúdo. No entanto, para ter êxito na escolha dos documentos, o analista precisa cumprir as seguintes regras: regra da exaustividade, que exige que nenhum documento deve ser deixado de fora; regra da homogeneidade, esta regra exige que a seleção dos documentos deva ter o mesmo tema para que permita a comparação e a última regra, que é a regra da pertinência que cobra que os documentos devam guardar correlação com os objetivos da análise.

Ainda na pré-análise o analista formula os objetivos, estes são os objetivos em geral, também formula o quadro teórico/pragmático, em que os resultados da análise serão tratados. A respeito da formulação de objetivos, Biagini (2013, p. 91) coloca que se os objetivos forem realizados tornam-se alicerces para as leituras dos documentos.

Continuando a pré-análise, o analista deve providenciar a referenciação dos índices e a elaboração dos indicadores, que são elementos de marcação para permitir extrair das comunicações a essência de sua mensagem. É nesta etapa que há as operações de recorte do texto em unidades comparáveis de categorização para análise temática e de algumas das modalidades de codificação para o registro dos dados (BARDIN, 2010, p. 126).

A última tarefa que 0 analista deve fazer na pré-análise é providenciar a preparação do material, que objetiva transformar o material por padronização e por equivalência. Para levar adiante essa etapa, deve ser feita edição do material, extração de muitas cópias para possibilitar os recortes das mensagens e também a numeração dos elementos do corpus.

Cumprindo mais uma etapa da metodologia, sem sair da organização da análise, o pesquisador adentra na exploração do material e nesta fase "ocorre à 
descrição analítica, a qual diz respeito ao corpus (qualquer material textual coletado) submetido ao estudo aprofundado, orientado pelas hipóteses e referenciais teóricos" (MOZZATO; GRZYBOVSKI, 2011, p. 735).

Ao cumprir a exploração do material, o analista deve fazer (BARDIN, 2010) a definição das categorias, classificando os elementos constitutivos de um conjunto caracterizados por diferenciação e realizando o reagrupamento por analogia por meio de critérios definidos previamente no sentido de propiciar a realização da inferência.

Além da ação anterior, o pesquisador na exploração do material vai identificar as unidades de registro com o objetivo de fazer a categorização e a contagem frequencial. Esta é uma ação para identificar a unidade de significação, captando os sentidos das comunicações em uma tarefa para codificar segmentos de conteúdo que se mostrem como unidade base.

Na última tarefa desta etapa, o analista deve identificar as unidades de contexto nos documentos para que the permita compreender as unidades de registro. Esta é uma operação que tem o intuito de individualizar a unidade de compreensão, como facilitadora, na codificação das unidades de registro de um segmento de uma mensagem estudada.

A fase final da etapa organização da análise é o tratamento dos resultados obtidos (em bruto) e sua interpretação. Nesta fase "os resultados em bruto são tratados de maneira a serem significativos ( $<<$ falantes $>>$ ) e válidos.". O pesquisador pode fazer operações estatísticas, simples ou até complexas, que possibilitem condensar e pôr em destaque as informações fornecidas pela análise (BARDIN, 2010, p. 127).

A respeito da organização da análise, Bardin (2010, p. 127) coloca que tendo "à disposição resultados fiéis e significativos, pode o analista propor inferências e adiantar interpretações a propósitos dos objectivos previstos -, ou que digam respeito" ao surgimento de resultados inesperados.

Feita a pré-análise, onde analista já se depara com um elevado nível de exigência e de minúcias própria do método, deve o pesquisador ir para o trabalho de preparação do material com o objetivo de codificar e categorizar os 
recortes. Na verdade, essa preparação já vem ocorrendo desde o início da etapa organização da análise, pois se o pesquisador cumprir todas as etapas lá colocadas, praticamente disporá do material pronto para o estudo.

Após ter reunido o material e o preparado por meio da edição e recortes dos textos (sintagmas), que pode ser feito apenas com destaque no corpo de cada mensagem, esses destaques devem ser numerados. Feito isso se deve juntar os recortes sob o prisma da padronização temática ou o termo que se equivalha, por exemplo: Atender respeitando a sua vontade do cliente (padrão) ou fechar a negociação respeitando o momento negocial (equivalência de respeitar a vontade do cliente).

Outro objetivo da preparação do material, além da transformação do material por padronização e equivalência, é a transformação linguística dos sintagmas.

A preparação dos sintagmas possibilita ao analista cumprir as etapas de codificação e de categorização, essenciais para a obtenção dos resultados.

Com o material de estudo preparado, o analista realiza a codificação antes da categorização. Ao codificar, o pesquisador transforma os dados brutos do texto em uma representação do conteúdo do que foi estudado no corpus, obtendo também neste trabalho as características das mensagens que podem ser escritas ou verbais.

Para que haja êxito no esforço de codificação, há técnicas que precisam ser seguidas. A primeira delas é o recorte, que pode ser uma frase, uma palavra isolada, palavras em conjunto, que indiquem uma relevância para a análise. Por meio do recorte é que são selecionadas as unidades de registro e as unidades de contexto. A segunda técnica que o pesquisador precisa ter em mente ao empreender a categorização é a da enumeração: o modo de se contar. Por exemplo: Pode contar quantas vezes uma palavra aparece nas mensagens, ou, em que posição aparece nos textos do corpus, etc.

A última técnica a ser empregada na codificação é a classificação $e$ agregação; ao aplicar essa técnica, o pesquisador avança no esforço de formar categorias. Por exemplo: ele seleciona todos os sintagmas que guardem 
referência com a palavra dor. Todo recorte que se referir a dor será separado, depois se seleciona dentro do vocábulo dor, os recortes que se refiram a dor de cotovelo, física e psicológica, separando ambas. Em tese, há duas categorias, uma que agregará tudo que se referir ao cotovelo que dói e a outra à dor dos sentimentos de amor não correspondido.

Mas a codificação deve ser feita, tanto para as unidades de registro quanto para as unidades de contexto. É importante ressaltar que o analista deve ter em mente que a ordem para fazer os recortes é sempre semântica (das significações), se não indicar um signo, deve ser revista a escolha do sintagma.

Para fins de facilitar a escolha de uma unidade de registo, o Quadro 1 foi incluído com a síntese das principais unidades utilizadas (BARDIN, 2010).

Quadro 1 - Unidades de registro mais utilizadas

\begin{tabular}{|c|c|c|}
\hline $\begin{array}{cc}\text { UNIDADE } & \text { DE } \\
\text { REGISTRO } & \end{array}$ & DESCRIÇÃO & FINALIDADE OU USO \\
\hline A palavra & $\begin{array}{l}\text { Todas as palavras são importantes } \\
\text { ou pode se reter as palavras-chave ou } \\
\text { as palavras-tema ou categorias de } \\
\text { palavras: substantivos, adjetivos, } \\
\text { verbos, advérbios, etc. }\end{array}$ & $\begin{array}{ccc}\text { Fito de } & \text { estabelecer } \\
\text { quocientes. } & & \end{array}$ \\
\hline O tema & $\begin{array}{l}\text { Fazer análise temática consiste } \\
\text { em descobrir os núcleos de sentido } \\
\text { que compõem a comunicação e cuja } \\
\text { presença pode significar alguma coisa } \\
\text { para o objetivo escolhido. } \\
\text { É uma regra de recorte do } \\
\text { sentido. }\end{array}$ & $\begin{array}{l}\text { Utilizado como unidade de } \\
\text { registro para estudar motivações } \\
\text { de opiniões, de atitudes, de } \\
\text { valores, de crenças, de } \\
\text { tendências, etc. }\end{array}$ \\
\hline $\begin{array}{l}\text { O objeto ou } \\
\text { referente. }\end{array}$ & $\begin{array}{l}\text { É tema-eixo, em redor dos quais o } \\
\text { discurso se organiza. }\end{array}$ & $\begin{array}{l}\text { Usa-se para recortar o texto } \\
\text { em função dos temas-eixo, } \\
\text { agrupando-se à sua volta tudo o } \\
\text { que o locutor exprime a seu } \\
\text { respeito. }\end{array}$ \\
\hline O personagem & $\begin{array}{l}\text { O ator social pode ser escolhido } \\
\text { como unidade de registro desde que } \\
\text { indicado na análise categorial. }\end{array}$ & $\begin{array}{l}\text { Uso em obras de ficção, } \\
\text { artigos de jornais, manuais } \\
\text { escolares, etc. Pode ser } \\
\text { combinada com outros tipos de } \\
\text { unidade. }\end{array}$ \\
\hline $\begin{array}{l}\text { O } \\
\text { acontecimento }\end{array}$ & $\begin{array}{l}\text { No caso de relatos e de narrações a } \\
\text { UR pode ser o acontecimento. }\end{array}$ & $\begin{array}{l}\text { Serão recortados em unidades } \\
\text { de ação. }\end{array}$ \\
\hline O documento & $\begin{array}{l}\text { O documento ou unidade de gênero } \\
\text { (um filme, um artigo, um livro) pode } \\
\text { servir de UR desde que tenha uma } \\
\text { dimensão global. }\end{array}$ & $\begin{array}{l}\text { Uso em análise rápida e com } \\
\text { recorte puramente formal. } \\
\text { Pode ser identificado no } \\
\text { ponto de intersecção de unidades } \\
\text { perceptíveis (palavra, frase, } \\
\text { documento material) e unidades }\end{array}$ \\
\hline
\end{tabular}


Análise de conteúdo em termos de Bardin aplicada à comunicação corporativa sob o signo de uma abordagem teórico-empírica

\begin{tabular}{|l|l|l|}
\hline & & $\begin{array}{l}\text { semânticas (temas, } \\
\text { acontecimentos, indivíduos). }\end{array}$ \\
\hline
\end{tabular}

Fonte: Bardin (2010). Nota: Quadro elaborado pelos autores.

Como foi dito acima, a segunda codificação é da codificação da unidade de contexto, que é a unidade de compreensão, cujo propósito é codificar a unidade de registro. Esta unidade corresponde ao segmento da mensagem que possibilita a significação precisa da unidade de registro (BARDIN, 2010, p. 133).

Codificar as unidades de contexto exige do pesquisador mais atenção, pois a escolha adequada destas unidades permite que se faça uma análise avaliativa de melhor qualidade, sendo que para isso deve atentar para os critérios de custo e pertinência, pois se a unidade de contexto for muito longa, exigirá dele mais tempo para fazer uma análise válida, se for curta, pode dificultar ou até impedir o trabalho de análise. Bardin (2010, p. 133) finda por orientar que a dimensão ótima depende do material trabalhado e do referencial teórico.

A última etapa da codificação é estabelecer as regras de enumeração, que é o modo de contagem das unidades de registro.

A respeito dessas regras de enumeração, Bardin (2010, p. 134) faz uma distinção didática, a autora define "a unidade de registro - o que se conta - e a regra da enumeração - o modo de contagem".

As regras de enumeração são repletas de detalhes, só com muita prática um pesquisador as domina de ofício, por esta razão e para facilitar a compreensão dos diversos tipos, todos eles estão reproduzidos ipsis litteris (BARDIN, 2010, p. 134-140):

- A presença ou ausência de elementos de significação;

- A frequência: com base no postulado que a importância do registro aumenta com a frequência da aparição;

- A frequência ponderada: Pode ser utilizada na identificação de um elemento é mais importante que outro. A ponderação pode corresponder a uma decisão tomada anteriormente, pode também, traduzir a intensidade de um elemento;

- A intensidade: A medida de intensidade com que cada elemento aparece é indispensável na análise dos valores (ideológicos, 
tendências) e das atitudes. Bardin (2010, p. 137) orienta que para avaliar o grau de intensidade a codificar pode se basear em critérios precisos: intensidade (semântica) do verbo, tempo do verbo (condicional, futuro, imperativo, etc.), advérbios de modo, adjetivos e atributos qualitativos [...].

- A direção: A ponderação da frequência traduz um caráter quantitativo (ponderação) ou qualitativo: a direção. A direção pode ser favorável, desfavorável ou neutra. Para tanto atribui-se aos elementos do texto um sinal (índice qualitativo) ou uma nota. Deve-se graficamente realizar uma escala de perfis para demonstrar a representação dos resultados.

- A ordem: A ordem de aparição das unidades pode indicar relevância do tema em um quadro de inferência.

- A co-ocorrência: A co-ocorrência é a presença simultânea de duas ou mais unidades de registro numa unidade de contexto. A medida de co-ocorrência (análise de contingência) dá conta da distribuição dos elementos e da sua associação (BARDIN, 2010, p. 134-140).

Feita a codificação das unidades de registro e das unidades de contexto, agora, o analista precisa classificar o conjunto de recortes ou elementos relativamente dispersos selecionados nas etapas anteriores, mas só classificar não permite a realização da análise, para obter resultados o pesquisador deve reagrupar os sintagmas por analogia, atentando para os seguintes critérios (BARDIN, 2010, p. 145): semântico (categorias temáticas), sintático (os verbos e os adjetivos), léxico (classificação das palavras segundo o seu sentido, com emparelhamento dos sinônimos e dos sentidos próximos) e expressivo (classificam as diversas perturbações da linguagem).

Por ser uma etapa complexa, o analista precisa ter amplo domínio do referencial teórico da metodologia e, até, leituras do desenvolvimento de análises de conteúdo como a existente no final do livro de Pagès (2008), tanto que Bardin (2010, p. 146) leciona alguns cuidados ao dizer que para "classificar elementos em categorias impõe a investigação do que cada um deles tem em comum com outros. O que vai permitir o seu agrupamento é a parte comum existente entre eles". Sobre este aspecto Selltiz (1975, p. 382) complementa ao dizer que a classificação exige do pesquisador exatidão e atenção para a validade dos dados. 
A categorização é feita em duas etapas: o inventário, quando se isola os elementos; e a classificação, que implica em repartir os elementos e buscar ou impor um nível de organização às mensagens e tem por objetivo principal permitir, por "condensação, uma representação simplificada dos dados em bruto".

A análise de conteúdo se assenta, de modo implícito, na crença de que a "categorização (passagem de dados em bruto a dados organizados) não introduz desvios (por excesso ou por recusa) no material, mas que dá a conhecer índices invisíveis, ao nível dos dados em bruto" (BARDIN, 2010, p. 147).

Ciente dessa complexidade de execução, ao se buscar categorizar os sintagmas, Bardin (2010, p. 147-148) veio em socorro e elaborou critérios de qualidade para facilitar a escolha das boas categorias, que foram sintetizadas no Quadro 2.

Quadro 2 - Critérios de qualidade de escolha das boas categorias por Bardin

\begin{tabular}{|l|l|}
\hline \multicolumn{1}{|c|}{ CRITÉRIO DE QUALIDADE. } & \multicolumn{1}{|c|}{ DESCRIÇÃO } \\
\hline A exclusão mútua & $\begin{array}{l}\text { Ser classificada em apenas uma categoria. Não existir } \\
\text { ambiguidades no momento do cálculo (multicodificação). }\end{array}$ \\
\hline A pertinência. & $\begin{array}{l}\text { A categoria é pertinente quando está adaptada ao } \\
\text { material escolhido, e quando pertence ao quadro teórico } \\
\text { definido. }\end{array}$ \\
\hline A objetividade e a fidelidade. & $\begin{array}{l}\text { O organizador da análise deve definir claramente as } \\
\text { variáveis que trata, assim como deve precisar os índices } \\
\text { que determinam a entrada de um elemento numa } \\
\text { categoria. }\end{array}$ \\
\hline A produtividade & $\begin{array}{l}\text { Um conjunto de categorias é produtivo se fornece } \\
\text { resultados férteis: férteis em índices de inferências, em } \\
\text { hipóteses novas e em dados exatos. }\end{array}$ \\
\hline
\end{tabular}

Fonte: Bardin (2010). Nota: Quadro elaborado pelos autores.

Para que o pesquisador não fique apenas nos conceitos, a autora também apresentou alguns exemplos de conjuntos categoriais, dispostos no Quadro 3. Importante destacar que por ser um método de pesquisa qualitativo, os conjuntos exemplificados são de grande valia para um pesquisador iniciante no método.

Quadro 3 - Exemplos de conjuntos de categorias (resumido) 
Análise de conteúdo em termos de Bardin aplicada à comunicação corporativa sob o signo de uma abordagem teórico-empírica

\begin{tabular}{|l|l|}
\hline CONJUNTO CATEGORIAL & EXEMPLOS DE CATEGORIA \\
\hline Análise dos valores. & $\begin{array}{l}\text { Valores fisiológicos; } \\
\text { Valores sociais; } \\
\text { Valores práticos; }\end{array}$ \\
\hline Análise dos fins e dos meios & $\begin{array}{l}\text { Categorias das finalidades; } \\
\text { Categorias dos métodos. }\end{array}$ \\
\hline Análise da interação & $\begin{array}{l}\text { Paciente: a) hostilidade; b) referente; } \\
\text { Terapeuta: a) Reações de aproximação; b) Reações de } \\
\text { Evitamento. }\end{array}$ \\
\hline $\begin{array}{l}\text { Análise de um estado } \\
\text { psicológico }\end{array}$ & Ansiedade, ira, depressão, sociabilidade, hostilidade, etc. \\
\hline \multicolumn{1}{|c|}{ Análise de imprensa } & Os ócios (a gastronomia, os presentes, os castelos, etc.). \\
\hline \multicolumn{2}{|c|}{ Fonte: Bardin (2010). Nota: Quadro elaborado pelos autores, adaptando termos da fonte. } \\
\hline
\end{tabular}

A última parte desse percurso teórico é a interpretação dos resultados feita na Análise de Conteúdo por meio da inferência, que para Bardin (2010, p. 41) é a "operação lógica, pela qual se admite uma proposição em virtude da sua ligação com outras proposições já aceitas como verdadeiras".

Para ter êxito no uso desse modo de interpretação de resultados, o pesquisador, nesta altura da pesquisa, já deve ter pleno domínio do referencial teórico e que a hipótese de pesquisa claramente delimitada tenha Ihe permitido confrontar os achados com esse referencial, mas, mais uma vez, o analista precisa dominar as orientações teóricas da Análise de Conteúdo, agora com relação ao olhar, no sentido de obter as respostas que precisa diante dos problemas que a metodologia está apta a responder, ou seja:

- O que é que levou a determinado enunciado? Este aspecto diz respeito às causas ou antecedentes da mensagem;

- Quais as consequências que determinado enunciado vai provavelmente provocar? Isto refere-se aos possíveis efeitos das mensagens (por exemplo: os efeitos de uma campanha publicitária, de propaganda) (BARDIN, 2010, p. 41, grifo nosso).

Para que possa obter uma interpretação confiável, o analista tem que também observar que formas de inferências existem, Bardin (2010, p. 167) leciona que há dois tipos de inferências. Há as inferências específicas, exemplificada por uma pergunta focada em um propósito, por exemplo: "Será que o pais A vai atacar o pais B?". Mas há também as inferências gerais, 
exemplificada assim: quando se pretende identificar se existe uma correlação do alerta de determinado risco vem da prevenção a ele ou se este risco já se configurou em prejuízo.

Feita essa síntese da parte teórica da metodologia o artigo se reportará à sua aplicação empírica.

\section{Aplicação empírica da análise de conteúdo}

Nas próximas páginas será feita a apresentação resumida do uso da metodologia por meio dos achados oriundos de uma pesquisa empírica. Essa pesquisa foi motivada pela crescente emissão de mensagens relacionados à conduta ética pelo segmento estratégico de uma instituição financeira. Tais mensagens explicitaram o impacto que a conduta ética estava causando na alta gestão, evidenciando tensões entre a prescrição ética normatizada e a forte cultura da empresa com primazia para o resultado (BEDANI, 2008).

Por 30 meses se acompanhou a emissão de 19 mensagens dirigidas aos gerentes da organização revelando a preocupação quanto a ética. As mensagens foram veiculadas a partir de junho de 2011 e perdurou para além do encerramento das coletas das mesmas, em dezembro de 2013.

Há que se salientar que essa organização teve ex-diretor envolvido no escândalo do mensalão.

Após analisar preliminarmente as mensagens do $\operatorname{corpus}^{\S}$ e confrontar as prescrições de conduta redigidas nelas e o contexto nos 30 meses da coleta das mensagens, se depreendeu delas o dilema de que atender todas as prescrições éticas se chocava com a cobrança absoluta por resultados, levando a concluir que a hipótese da pesquisa era a de que a comunicação na organização era contraditória e por isso gerava tensão nos gerentes gerais das agências.

Encontrada a hipótese da pesquisa, o analista adentrou na primeira fase da metodologia Análise de Conteúdo, a organização da análise, que é uma

\footnotetext{
$\S$ Coleção de textos da língua efetivamente em uso coligidos em livros, periódicos, documentos de todo tipo. (CORPUS, 2016)
} 
etapa longa e que engloba fases, que se levada a bom termo, impulsiona bem a pesquisa.

A pré-análise se iniciou com a leitura flutuante de cerca de 30 mensagens selecionadas por tipicidade e acessibilidade (VERGARA, 2007, p. 51), cuja característica primordial era versarem diretamente ou por indução sobre condutas éticas, também se definiu como o segundo parâmetro de escolha que se originassem do alto escalão da empresa.

No contexto da prática, a leitura flutuante se repetiu mais duas vezes até que a seleção final do corpus fosse concluída. O corpus foi composto por 19 mensagens formais, instrumentais e formativas que prescreviam condutas sobre ética nos negócios (MARCHIORI, 2010, p. 147).

Assim, em função da pré-análise, a pesquisa se direcionou para a análise de valores.

Então, segui a aplicação na pesquisa da fase exploração do material. Fase extensa, lenta, detalhada e que demandou muito tempo de dedicação à tarefa ao exigir várias releituras, um esforço contínuo para desnudar os sentidos de cada comunicação na busca de aclarar os sentidos ocultos, de identificar os discursos ideológicos e simbólicos, de desnudar as mensagens cifradas por um código de interpretação específico advindas da manipulação do imaginário (ENRIQUEZ, 1997, p. 7). Tudo isso foi reinterpretado com base no referencial teórico selecionado para a pesquisa, permitindo concretizar as análises de conteúdo.

Importa salientar que toda a etapa é de alta complexidade de condução e que pode haver algumas condições facilitadoras para o seu desenvolvimento, por exemplo: a familiaridade dos contextos da organização e da própria emissão das mensagens do corpus; familiaridade ou bom conhecimento da cultura organizacional.

É relevante trazer uma recomendação de ordem prática: Caso a pesquisa se desenvolva em uma organização, deve o analista se aprofundar no conhecimento da cultura organizacional predominante, pois ela induz muitos vieses da comunicação interna não explicitada. 
Também do ponto de vista do uso do método, estar inteirado dos conceitos, ter mentalizado exemplos de unidades de registro e de unidades de contexto e o papel de cada um no processo de análise vai facilitar muito a exploração do material.

Também nessa fase já se deve delinear o referencial teórico que vai embasar as análises, pois também permitirá que o analista faça a busca mais próxima ao que se quer pesquisar.

No caso da pesquisa empírica, foi nessa fase que já se identificou as primeiras contradições no corpus.

Na etapa exploração do material também foi realizada a análise textual, que é distinta da leitura flutuante por ser uma leitura com profundidade, que busca compreender cada conteúdo a partir de cada frase ou palavra encontradas nos textos selecionadas como importantes segundo os objetivos da pesquisa. Do ponto de vista de sua execução, a análise textual exige repetições até se esgotar a seleção das frases e palavras significativas do corpus.

Também como prática da análise textual, foi anotado ao lado de cada mensagem as ideias centrais de cada uma, às vezes com um todo coerente, às vezes traziam contradições, como no contexto de uma mensagem de 2011, emitida no último mês do primeiro semestre, onde dizia que era uma oportunidade de se cumprir as metas ao mesmo tempo em que alertava para só fazer com autorização formal do cliente. O recado interpretado, que se infere da mesma, é que ainda faltava muito para o item no país ser entregue e ela era muito importante para a composição do lucro daquele semestre.

Para auxiliar a compilação das frases e palavras expressivas aos objetivos da pesquisa, uma planilha Excel foi desenhada com as seguintes colunas:

1 - Data de emissão; 2 - Órgão expedidor (Nível gerencial estratégico ou órgão tático); 3 -Título; 4 - Tema explícito; 5 - Tema implícito; 6 - Contexto; 7 - Se havia norma divulgada explicitamente; 8 - Palavras-chave.

Veja alguns exemplos de expressões separadas do corpus decorrentes da análise textual: rentabilizar a base de clientes, estratégia de elevar receitas, 
zelar pela preservação do modelo de gestão dos clientes; normativos aderentes a legislação em geral, análise disciplinar, condução, apuração, irregularidade, entre outras.

A análise textual é um procedimento anterior ao processo de codificação e de categorização, mas é por meio dela que vão despontando os sintagmas* que comporão as unidades de contexto.

A etapa seguinte, após procedimento de análise textual e seleção dos sintagmas, foi a codificação e resultou na definição das unidades de registro e das unidades de contexto, das categorias e dos temas.

Do ponto de vista da execução da codificação, o foco do estudo foi para o vocábulo ética e toda frase que levasse ao entendimento que a mensagem se referia a ela. Essa realidade despontou como a primeira situação a ser codificada. $\mathrm{O}$ código desenvolvido no projeto foi o uso de palavras-chave que agregaram várias frases essenciais (sintagmas), como exemplificado no Quadro 5. Todo o conjunto inicial de palavras-chave foi composto com 16 palavraschave, que agregavam dezenas de sintagmas.

Esse processo de seleção, com muito termos, cobrou a construção das unidades de registro, o que exigiu, ao longo da seleção, várias releituras dos sintagmas, como dos textos integrais. Observando-se, para a eficácia do uso desta metodologia, uma prática é fundamental: a da repetição sistemática da leitura dos elementos selecionados para a análise, da qual o analista não pode prescindir.

Desse processo de identificação, reflexão e montagem das mensagens pelo processo de agregação por similaridade de sentido emergiu duas situações fundamentais do âmago das mesmas, situações que se contrapunham ante a realidade das condutas profissionais presentes naquele contexto na empresa.

A primeira dessas situações expressava a intenção, de uma projeção que no futuro se tivesse um novo padrão de conduta desejado pela organização, a

\footnotetext{
** Unidade sintática que, na hierarquia da estrutura gramatical de uma língua, se situa entre a palavra e a oração (p.ex.: as rosas brancas).
} 
outra situação fundamental fala da conduta real, do que estava ocorrendo no momento da sua veiculação e em passado recente.

Com base nessas duas especificações, foi factível a construção das duas unidades de registro que compuseram a análise de quatro das cinco categorias, que serão mais à frente explicitadas, assim se tem:

O discurso institucional projetivo (desejo da empresa que haja uma nova conduta profissional interna) e o discurso institucional real (revelação das condutas existentes e não desejadas pela organização).

Do ponto de vista da execução da metodologia, criar as unidades de registro e as unidades de contexto demanda tempo. Mas para as unidades de contexto essa tarefa é facilitada pela análise textual, pois quase todos os sintagmas selecionados formam essas unidades, situação que vem de encontro com o conceito formulado por Bardin (2010, p. 131), que declara "a unidade de significação que se liberta naturalmente de um texto analisado segundo certos critérios relativos à teoria que serve de guia à leitura, sendo que o texto pode ser recortado em ideias constituintes", com ênfase na busca do sentido e não da forma.

No caso específico da pesquisa, antes da composição das unidades de contexto, denominamos os termos mais significativos para os objetivos da pesquisa de frases essenciais (Quadro 5). A essencialidade decorreu da percepção preliminar que elas poderiam possibilitar uma interpretação final na pesquisa.

As unidades de contexto são as frases selecionadas pelo recorte das mensagens trabalhadas e reagrupadas conforme a categoria, a unidade de registro, o tema e a unidade de contexto elementar.

A seleção das unidades de contextos foram os recortes selecionados como frases essenciais (ver Quadro 5).

Mesmo não fazendo parte do teor da obra de base feita por Bardin (2010) para que o analista desenvolvesse a contento uma análise de conteúdo, um facilitador para a construção das categorias foi incorporado ao esforço interpretativo, cuja denominação foi cunhada por Rocha (2008, p. 24). Este 
autor denominou uma especialização da unidade de contexto, dizendo que esse refinamento nomeava-se unidade de contexto elementar.

A realidade da pesquisa impôs, ao se concluir a construção das unidades de registro e da seleção das unidades de contexto para o quadro de frases essenciais, um termo que refinasse estas unidades e isto foi atendido pela idealização das unidades de contextos elementares e apresentadas nos quadros-síntese das categorias antes das respectivas unidades de contexto, situação exemplificada no Quadro 6.

Embora a construção e escolha das unidades de registro, das unidades de contexto, do tema e das unidades de contexto elementar estejam aparentemente estanques ao apresentá-las sob a orientação teórica, elas vão surgindo e se construindo quase ao mesmo tempo, dificultando sobremaneira o processo de categorização.

Tanto que a codificação quanto a categorização são a parte mais difícil da aplicação do método, pois encontrar o ponto ótimo para se proceder a ambas, especialmente a categorização, em alguns momentos se assemelhou a um estado de arte, ainda que seus parâmetros técnicos estivessem à mão, de maneira que sua aplicação exige de um iniciante muita paciência e um espírito investigativo sem as amarras dos conceitos básicos.

Por ser muito complexo o emprego dessa metodologia, ela desde início exige eficácia e tanto mais ao se chegar na fase de categorização, que cobra muito tempo, uma acuidade mental bem trabalhada, uma grande capacidade de abstração para juntar os sintagmas e principalmente organização no pensar.

Um alerta importante: quando chega o momento de compor as categorias, diante de todo o material que já está disponível o raciocínio tende a ficar confuso, com um emaranhado de sintagmas que parecem soltos no ar.

Um dos livros que pode auxiliar um pesquisador a superar essa fase da aplicação da análise de conteúdo é o Dicionário Analógico da Língua Portuguesa - ideias afins/thesaurus de Azevedo (2010).

Como exercício prático para a construção de uma categoria, foi selecionado o vocábulo ética no Dicionário Analógico da Língua Portuguesa - 
ideias afins/thesaurus (AZEVEDO, 2010) para auxiliar na compreensão de como elaborar as categorias.

A palavra ética nele tem as seguintes ideias afins:

- Ética como: preceito, princípio, norma: determinação, compromisso, norma: instrução (AZEVEDO, 2010, p. 321);

- Ética como: comportamento, cultura, relacionamento (AZEVEDO, 2010, p. 146);

- Ética como: conduta, comportamento, procedimento, gestão, liderança, norma (regra de procedimento), postura, orientação, atitude, linha de ação. (AZEVEDO, 2010, p. 318).

Evoluindo na demonstração na estruturação de Azevedo (2010) foi possível identificar o que unia cada sentido da palavra ética. Essa união foi feita por um termo aglutinador. Por exemplo: Ética como dever remete à responsabilidade, à obediência, ao zelo, entre outras palavras que exprimam um dever. Portanto, dever é o termo aglutinador.

Para maior clareza desse raciocínio, está reproduzido abaixo como o autor do dicionário categorizou um dos sentidos para ética. 0 exemplo foi extraído das ideias afins no 926 e 927 (AZEVEDO, 2010, p. 449-450):

- Classes das palavras: VI - afeições;

- Divisões: morais;

- Divisão IV: afeição moral;

- 10) Obrigações:

- Dever (vocábulo 926): responsabilidade; compromisso, obrigação, comprometimento, dever imperioso, obediência, observância, disciplina, zelo, obrigatório, compulsório;

- Transgressão (vocábulo 927): inobservância, negligência, desobediência, vocação, falha, desviar-se do dever, não cumprir (lei, normas, etc.), transgredir, desidioso.

Em que pese esse grande auxílio, o desenvolvimento do raciocínio ainda se mostrava difícil para se fazer a categorização, até que se formulou uma figura à semelhança do feito por Bardin (2010, p. 25), tendo por base a 
seguinte classificação de cunho empírico e dando conta da existência de tensões na organização pesquisada e distribuídas em três perspectivas: I Econômico - Competitivo Dominante; II - Econômico - Normativo Dominante e III - Econômico - Comunicação Dominante. (Figura 1)

Com relação à classificação, as tensões organizacionais estão evidenciadas no quadro 4, com a seguinte dimensão para análise:

1 - Tipo de tensão organizacional; 2 - Evidências textuais identificadas no corpus estudado; 3 - Referencial teórico relacionado ao tipo de tensão e às evidências textuais.

Mas ao fazer o vínculo entre os tipos de tensões com as evidências textuais, trazendo também os referencias teóricos, se criou um preâmbulo para todo o processo de interpretação, pois ao fazer esse trabalho se iniciou uma rudimentar inferência, que cresceu ao longo de todo o estudo e se consolidou com as definições das categorias e sua composição final espelhada nos quadros-síntese.

Quadro 4 - Tensões organizacionais

\begin{tabular}{|c|c|c|}
\hline TIPO DE TENSÃO & EVIDÊNCIAS TEXTUAIS. & REFERENCIAL TEÓRICO \\
\hline $\begin{array}{l}\text { I - ECONÔMICO - } \\
\text { COMPETITIVO } \\
\text { DOMINANTE: } \\
\text { O dever ser: cumprir } \\
\text { metas; não cumprir } \\
\text { metas. }\end{array}$ & $\begin{array}{l}1 \text { - Entregar as metas, } \\
\text { atingir resultados propostos, } \\
\text { superar desafios; } \\
2 \text { - Rentabilizar clientes, } \\
\text { Modelo de gestão de } \\
\text { clientes; } \\
4 \text { - Cobrar mais tarifa, up } \\
\text { grade, oportunidade para } \\
\text { cumprir o acordo de } \\
\text { trabalho. }\end{array}$ & $\begin{array}{l}\text { Também apontam para a "Zona } \\
\text { da ideologia Oficial - Zona A, dos } \\
\text { grandes princípios" da organização, } \\
\text { neste caso, para o princípio } \\
\text { predominante da cultura de negócios: } \\
\text { entregar as metas, cuja tensão é } \\
\text { permanente, que não tem alívio nem } \\
\text { quando as supera (PAGĖS, 2008, p. } \\
\text { 89). }\end{array}$ \\
\hline $\begin{array}{l}\text { II - ECONÔMICO - } \\
\text { NORMATIVO } \\
\text { DOMINANTE: } \\
\text { O dever ser: cumprir } \\
\text { normas; não cumprir } \\
\text { normas. }\end{array}$ & $\begin{array}{l}1 \quad-\quad \text { Venda casada, } \\
\text { cumprimento de regra, } \\
2 \text { - "Não fazer nada mesmo } \\
\text { coagido por fatores externos } \\
\text { (pressão de gerentes), } \\
\text { decisão é sempre individual, } \\
\text { as consequências são } \\
\text { sempre individuais; } \\
3 \text { - Não fazer nada na base } \\
\text { da confiança; }\end{array}$ & $\begin{array}{l}\text { A tensão aqui guarda referência } \\
\text { com a "Zona Intermediária consciente } \\
\text { (zona B)", que mistura compromisso } \\
\text { com a zona da ideologia oficial e os } \\
\text { valores pessoais (PAGĖS, 2008, p. } \\
\text { 89). } \\
\text { Também indicam os valores } \\
\text { pessoais expressos na confiança de } \\
\text { seus pares no dia a dia, na prática da } \\
\text { atividade profissional. } \\
\text { Ela se reflete no aforismo não } \\
\text { fazer nada na base da confiança. }\end{array}$ \\
\hline TIPO DE & EVIDENCIAS TEXTUAIS. & REFERENCIAL TEÓRICO \\
\hline III & $1-\mathrm{OB}$ & \\
\hline
\end{tabular}




\begin{tabular}{|c|c|c|}
\hline 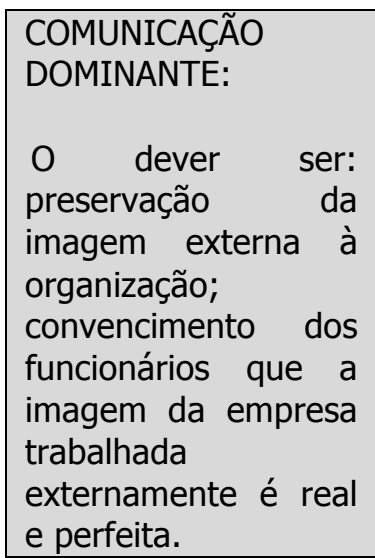 & $\begin{array}{l}\text { respeitadora das leis; } \\
2 \text { - Compromisso público de } \\
\text { ser empresa ética, pacto } \\
\text { pela integridade, obrigação } \\
\text { legal a cumprir de combate } \\
\text { a corrupção, práticas } \\
\text { empresariais para a } \\
\text { promoção da integridade, } \\
\text { profissional qualificado; } \\
4 \text { - Resultados sustentáveis, } \\
\text { assegurar a imagem da } \\
\text { empresa de solidez, } \\
\text { segurança e marca, }\end{array}$ & $\begin{array}{l}\text { de tensão se refletem no reforço dos } \\
\text { grandes princípios da "Zona da } \\
\text { Ideologia Oficial" - "Zona A" em } \\
\text { confronto com o esforço de anulação } \\
\text { da "Zona dos Valores Pessoais" (Zona } \\
\text { "C") para que as contradições } \\
\text { percebidas e camufladas pela } \\
\text { organização no "nível descritivo", } \\
\text { como fato e não como conhecimento } \\
\text { (PAGĖS, 2008, p. 89). }\end{array}$ \\
\hline
\end{tabular}

Fontes: 1) Coluna Evidências Textuais, corpus de mensagens emitidas pelo Banco X;

2) Coluna Referencial Teórico, Pagès (2008) e Bedani (2008).

Nota: Quadro elaborado pelos autores.

O conjunto de dilemas dispostos na Figura 1 é que se entende como dominante em relação a todos os aspectos em que a organização coloca a sua influência, conforme evidências coletadas nas análises.

No sentindo de permitir ao analista um esboço para a categorização final, elaborou-se um quadro com palavras-chave preliminares, antes de serem coligidas em uma categoria, como se lê no Quadro 5.

Fazer um quadro semelhante é útil por permitir uma visão concentrada do que é importante na seleção dos sintagmas.

Figura 1 - Tensões Organizacionais

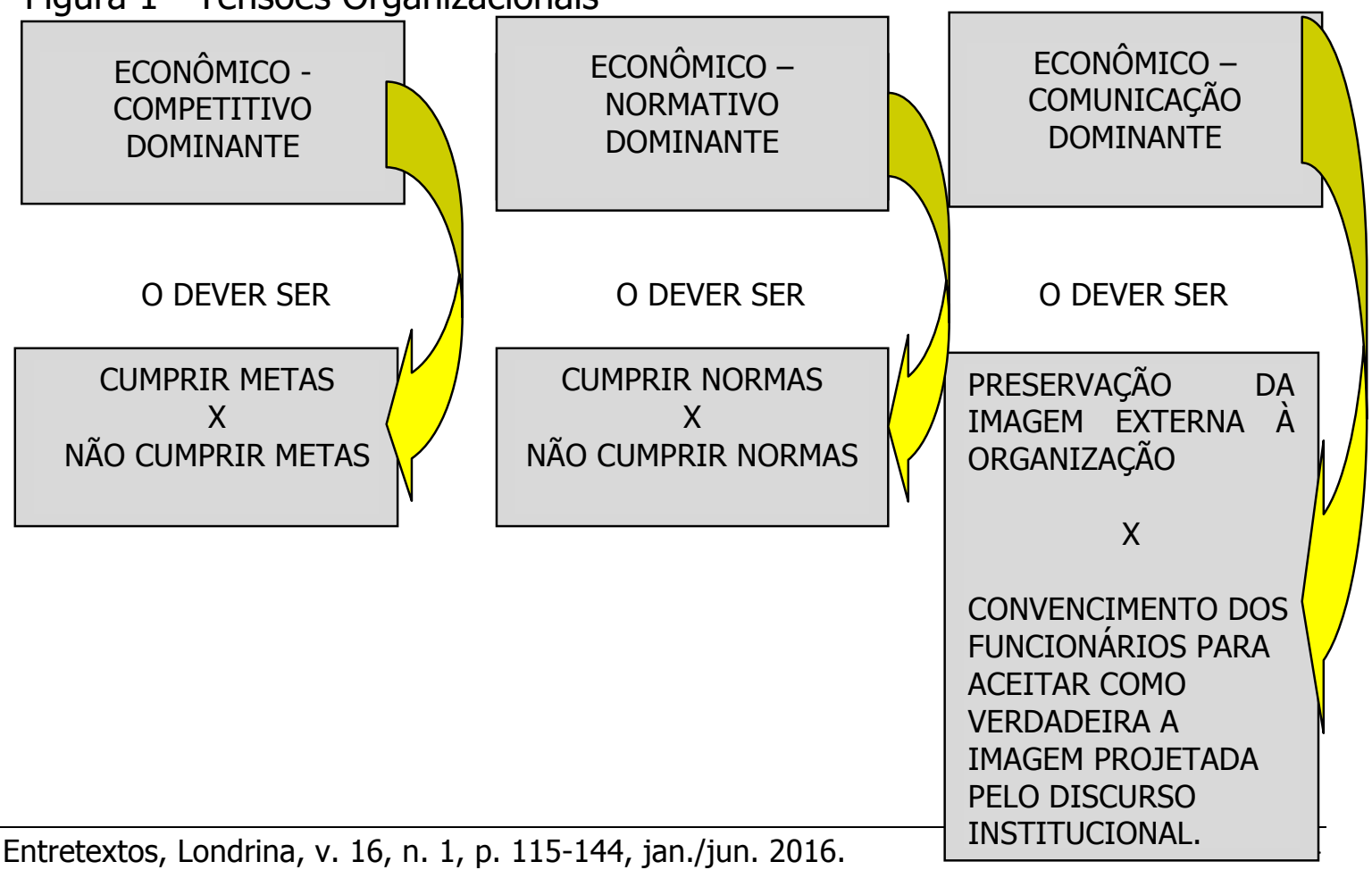


Fonte: Autores.

Cumprir Metas, por exemplo, não se tem outra conduta que não cumprir as metas, assim afirma Bedani (2008, p. 258) ao dizer que na empresa a perspectiva da lucratividade gera "um círculo vicioso, com práticas eficazes no sentido econômico e nefastas na perspectiva dos seres humanos que participam do processo, inclusive com a existência de condutas não éticas. "

Esta é uma situação que demonstra a Hipótese de Pesquisa ao revelar o conflito da comunicação (coluna 3 da figura 1) com o aforismo cumprir metas (coluna 1 da figura 1), incessante no discurso, na prática e nas ações de afastamento dos que não conseguem cumprir as metas, razão em muitas ocasiões para a ética seja desrespeitada.

\begin{tabular}{|c|c|c|}
\hline $\begin{array}{l}\text { PALAVRA } \\
\text { - CHAVE }\end{array}$ & FRASES ESSENCIAIS & $\begin{array}{lc}\text { CATEGORIZAÇÃO } & \text { ANTE } \\
\text { TENSÃO ORGANIZACIONAL. }\end{array}$ \\
\hline ZELAR & $\begin{array}{l}\text { - Venda casada, cumprimento de regra, } \\
\text { evitar mutuário do programa nacional de } \\
\text { agricultura familiar, risco político-governo, } \\
\text { risco de imagem, falta grave; } \\
\text { - Usar modelo gestão dos clientes conforme } \\
\text { idealizado, preservação; } \\
\text { - Não fazer nada mesmo coagido por } \\
\text { fatores externos (pressão de gerentes), } \\
\text { decisão é sempre individual, as } \\
\text { consequências são sempre individuais. }\end{array}$ & $\begin{array}{l}\text { - Tensão Econômico-Competitivo } \\
\text { dominante; Econômico-Normativo } \\
\text { Dominante e Comunicação- } \\
\text { Econômico Dominante. } \\
\text { - Tensão Econômico-Normativo } \\
\text { Dominante. } \\
\text {-Tensão Econômico-Comunicação } \\
\text { Dominante. }\end{array}$ \\
\hline $\begin{array}{l}\text { SER } \\
\text { ÉTICO }\end{array}$ & $\begin{array}{l}\text { - Realiza negócios no dia-a-dia com ética, } \\
\text { ter ética como princípio em todas as } \\
\text { práticas da empresa; } \\
\text { - Resultados sustentáveis, assegurar a } \\
\text { imagem da empresa de solidez, segurança } \\
\text { e marca; } \\
\text { - Ponto eletrônico, burlar, fidelidade dos } \\
\text { registros, falta grave a burla; } \\
\text { - Não compartilhar credenciais (chave). }\end{array}$ & $\begin{array}{l}\text { - Tensão Econômico-Competitivo } \\
\text { Dominante e Econômico- } \\
\text { Comunicação Dominante. } \\
\text { - Idem. } \\
\\
\text { - Tensão Econômico-Normativo } \\
\text { Dominante. } \\
\text { - Idem. }\end{array}$ \\
\hline $\begin{array}{l}\text { ESTRATÉ- } \\
\text { GIA }\end{array}$ & $\begin{array}{l}\text { - Upgrade de tarifas, elevar receita de } \\
\text { tarifas, mais resultado; } \\
\text { - Modelo de gestão de clientes; } \\
\text { - Combate a inadimplência, fórum } \\
\text { adimplência, presença do } 10 \text { gestor é }\end{array}$ & $\begin{array}{l}\text { - Tensão Econômico-Competitivo } \\
\text { Dominante. } \\
\text { - Tensão Econômico-Normativo } \\
\text { Dominante. } \\
\text {-Tensão Econômico-Competitivo } \\
\text { Dominante e Econômico- }\end{array}$ \\
\hline
\end{tabular}




\begin{tabular}{|l|l|l|}
\hline & $\begin{array}{l}\text { cobrada, responsabilidade gerencial, } \\
\text { profissional qualificado, exposição interna, } \\
\text { resultados sustentáveis. }\end{array}$ & Normativo Dominante. \\
\hline
\end{tabular}

Fonte: Autores.

Passada a fase do aprendizado, como realizar uma categorização correta? O trabalho se conduziu para uma categorização temática final e suas palavras-chave.

Por fim, a classificação das cinco categorias é resultante de 16 palavraschave e do conjunto das frases essenciais ou recortes temáticos (Exemplificadas no Quadro 5), que são os termos que orientam a racionalidade dos gestores da organização estudada.

Para cada categoria final, foram listadas as palavras-chave que a originaram, a saber:

Categoria I: Zelo Profissional.

Palavras-chave que originaram esta categoria: Clientes; ética; irregularidade; pressão do chefe; profissional qualificado; ser ético; trabalho consistente; zelar.

Categoria II: A Ideologia do Resultado Sustentável.

Palavras-chave que originaram esta categoria:

Estratégia; ética; oportunidade; profissional qualificado; resultados sustentáveis; resultados.

Categoria III: O Imaginário do Gestor Qualificado.

Palavras-chave que originaram esta categoria:

Clientes; discurso da empresa; estratégia; ética; imagem; irregularidade; profissional qualificado; resultados sustentáveis; ser ético; trabalho consistente; zelar.

Categoria IV: Projeção da Imagem Institucional Desejada Sobre os Funcionários.

Palavras-chave que originaram esta categoria:

Clientes; ética; imagem; profissional qualificado.

Categoria V: Concordância Cultural.

Esta categoria é subjacente às análises das quatro categorias principais e 
identificada como um pano de fundo das mesmas.

$\mathrm{Na}$ terceira fase veio o tratamento dos resultados, a inferência e a interpretação com base no referencial teórico. Algumas recomendações são importantes para realizar a análise dos dados qualitativos. Gray (2012, p. 400) indica que é preciso estar atento para que haja coerência com as hipóteses formuladas e, se for necessário, reescrevê-las, se os casos analisados forem desviantes; também é preciso levar em conta que o pesquisador não é observador neutro e, por fim, realizar a indução analítica com a transcrição dos dados, coletar/codificar/coletar na medida em que for lendo os documentos; depois revisar/corrigir notas/modificar códigos e suprimir códigos semelhantes.

De um ponto de vista da execução da pesquisa tratada neste artigo, a montagem dos quadros com cada categoria foi essencial para o tratamento dos resultados. Exemplificado no Quadro 6.

Mas de um modo geral, montar uma planilha, um painel, quadro ou qualquer outra ferramenta que dê ao analista uma visão unificada permite que os sucessivos retornos a uma das ferramentas facilitem a interpretação dos resultados pela inferência.

Outro aspecto voltado para a prática, é a escrita dos resultados. No caso da pesquisa, foi de muita utilidade escrever uma impressão geral (resumo) da interpretação de cada categoria e depois compor a interpretação completa, tal medida facilita a leitura posterior, pois funciona como uma apresentação da Inferência, introduzindo o leitor para estudo amplo dos resultados.

Outro cuidado que o analista deve ter é não ampliar em demasia os itens que serão interpretados, pois se isso ocorrer, o trabalho torna-se muito longo, tanto para fazê-lo quanto para ser ler.

Uma sugestão é que se limite em quatro pontos de interpretação por categoria, que também precisa estar limitada, a não ser que o trabalho seja desenvolvido por uma equipe, pois a divisão de trabalho que a caracteriza vai facilitar a execução de toda a pesquisa como da Inferência.

A sugestão final, com o sentido de facilitar a interpretação dos resultados com base no referencial teórico, é se imprimir apenas o referencial selecionado 
e compilado em uma prévia da pesquisa, complementando esse esforço deve se anotar ao lado de cada item a ser interpretado a página onde o conteúdo teórico a ser referenciado está localizado.

Para melhor compreensão, abaixo se fez uma reduzida recapitulação alguns tópicos do método de pesquisa e a análise dos resultados.

\section{Análise dos resultados}

Concluídas as etapas da metodologia qualitativa da Análise de Conteúdo, iniciamos a análise dos resultados. Para fins de visualização do percurso metodológico, desenhou-se a figura 2 , como síntese do método utilizado em termos empíricos.

Figura 2 - Representação gráfica simplificada da condução da análise de conteúdo $^{\dagger+}$

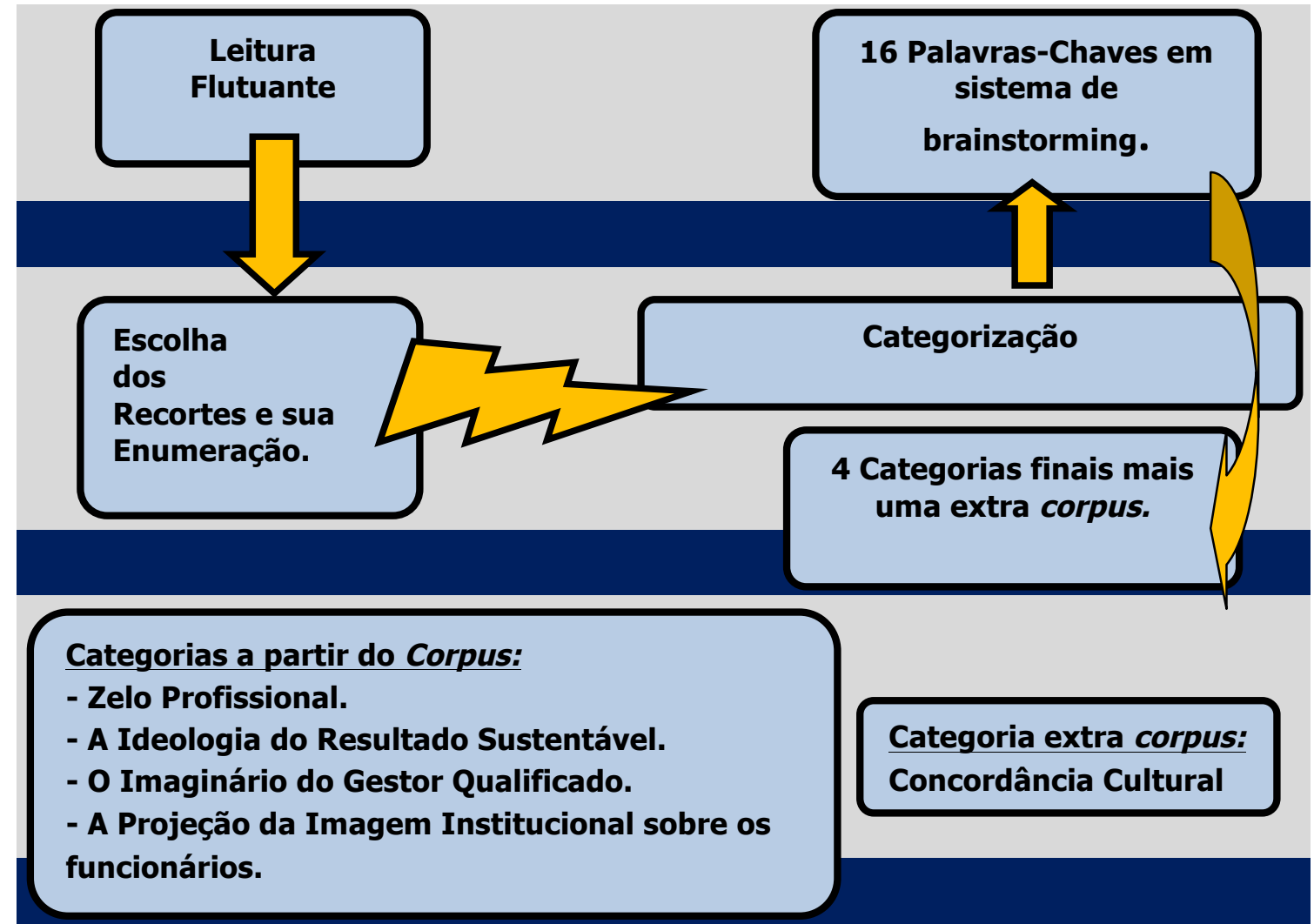

Fonte: Autores.

\footnotetext{
${ }^{+\dagger}$ Sistema de braisntorming: O uso do brainstorming se deu após a leitura das mensagens algumas palavras se repetiam ou tinham uma ênfase especial dado pelo emissor da mensagem, indicando que as mesmas representavam significado especial a ser estudo pela análise de conteúdo.
} 
A análise dos resultados se deu a partir das evidências coletadas nas mensagens do corpus e elas foram confrontadas com referencial teórico que propiciou a base para análise de conteúdo.

Aplicados os procedimentos metodológicos da análise de conteúdo, elaboraram-se cinco quadros-síntese, um para cada categoria, deles apenas um quadro-síntese foi trazido ao artigo para comentários. Cada quadro de uma categoria tem a seguinte composição: unidade de registro, tema, unidade de contexto elementar e unidade de contexto. Essa composição vai do geral para o específico, sendo que nesta parte do trabalho tende a ter mais itens para interpretação.

Com a construção dos quadros se procedeu à análise de conteúdo e seu confronto com a teoria de base para cada unidade de contexto. São cinco categorias finais, quatro encontradas a partir do corpus e a quinta categoria identificada a partir das evidências observadas nas análises de conteúdo das categorias do grupo.

As categorias são as seguintes:

GRUPO I - Identificadas no corpus:

- Zelo profissional;

- A Ideologia do Resultado Sustentável;

- O Imaginário do Gestor Qualificado;

- Projeção da Imagem Institucional Desejada sobre os Funcionários.

GRUPO II - Derivada das categorias do Grupo I:

- Concordância Cultural.

Para cada categoria foi construído uma síntese da interpretação, para em seguinte ser escrita a interpretação ampla. Tal medida foi feita para auxiliar a um estudioso que queira ter uma visão mínima do conteúdo interpretado, caso não necessite ler a análise de conteúdo completa.

Mas ter um quadro-síntese oferece um ganho, se o desejo for fazer uma análise de conteúdo específica para cada unidade de contexto, essa alternativa oferece facilmente a uma visão focada do sintagma.

Como modo de exemplificação da construção empírica de uma das 
Análise de conteúdo em termos de Bardin aplicada à comunicação corporativa sob o signo de uma abordagem teórico-empírica

categorias, abaixo se demonstra o quadro-síntese específico da categoria $A$ Ideologia do Resultado Sustentável, com as Unidades de Registro I e II, com o Tema I e II, com a Unidade de Contexto Elementar I e II e as Unidades de Contexto I e II.

Quadro 6 - Categoria: a ideologia do resultado sustentável

\begin{tabular}{|c|c|c|c|}
\hline $\begin{array}{l}\text { UNIDADE } \\
\text { DE } \\
\text { REGISTRO } \\
\text { I }\end{array}$ & TEMA I & $\begin{array}{l}\text { UNIDADE DE } \\
\text { CONTEXTO } \\
\text { ELEMENTAR I }\end{array}$ & UNIDADES DE CONTEXTO I \\
\hline & & & 1 - Usar a ética para fidelizar os clientes. \\
\hline & & & 2 - Atender com ética é atender bem. \\
\hline & & & $\begin{array}{l}3 \text { - Respeitar a vontade do cliente, postura } \\
\text { de qualidade, ética nos negócios, seguro de } \\
\text { vida. }\end{array}$ \\
\hline $\begin{array}{l}\text { Discurso } \\
\text { institucional } \\
\text { projetivo }\end{array}$ & $\begin{array}{l}\text { O resultado } \\
\text { como valor } \\
\text { social }\end{array}$ & $\begin{array}{l}\text { Ter a ética como } \\
\text { valor desejável } \\
\text { na geração dos } \\
\text { resultados }\end{array}$ & $\begin{array}{l}4 \text { - Ciclo virtuoso, resultados sustentáveis, } \\
\text { qualidade dos negócios }\end{array}$ \\
\hline & & & $\begin{array}{l}5 \text { - Satisfação dos clientes, resultados } \\
\text { sustentáveis, atendimento com ética, ciclo } \\
\text { virtuoso. }\end{array}$ \\
\hline & & & $\begin{array}{l}6 \text { - Vender com ética, agir com ética nos } \\
\text { negócios, satisfação dos clientes. }\end{array}$ \\
\hline & & & $\begin{array}{l}7 \text { - Parceria duradoura com os clientes, } \\
\text { sustentável, respeito à vontade do cliente, } \\
\text { ética nos negócios. }\end{array}$ \\
\hline $\begin{array}{l}\text { UNIDADE } \\
\text { DE } \\
\text { REGISTRO } \\
\text { II }\end{array}$ & TEMA II & $\begin{array}{l}\text { UNIDADE DE } \\
\text { CONTEXTO } \\
\text { ELEMENTAR II }\end{array}$ & UNIDADES DE CONTEXTO II \\
\hline \multirow{5}{*}{$\begin{array}{l}\text { Discurso } \\
\text { institucional } \\
\text { real }\end{array}$} & \multirow{5}{*}{$\begin{array}{l}\text { O resultado } \\
\text { como valor } \\
\text { único }\end{array}$} & \multirow{5}{*}{$\begin{array}{l}\text { Sua história é } \\
\text { contada pelo } \\
\text { resultado }\end{array}$} & $\begin{array}{l}1 \text { - Defesa negocial na flexibilização de peso } \\
\text { de restrição, evitar uso de termos vagos, } \\
\text { justificativas insuficientes. }\end{array}$ \\
\hline & & & $\begin{array}{l}2 \text { - Primar pela adimplência e maximização } \\
\text { dos resultados no desconto de cheques, } \\
\text { redução dos índices de inadimplência, } \\
\text { gerenciar com maior eficiência as operações. }\end{array}$ \\
\hline & & & $\begin{array}{l}3 \text { - Upgrade de tarifas, elevar receita de } \\
\text { tarifas, mais resultado. }\end{array}$ \\
\hline & & & $\begin{array}{l}4 \text { - Entregar as metas, atingir resultados } \\
\text { propostos, superar desafios. }\end{array}$ \\
\hline & & & $\begin{array}{l}5 \text { - "Cobrar mais tarifas dos clientes, } \\
\text { rentabilizar clientes", novo modelo de } \\
\text { relacionamento com clientes, "Cobrar mais } \\
\text { tarifa, upgrade, oportunidade para cumprir o } \\
\text { acordo de trabalho". }\end{array}$ \\
\hline
\end{tabular}

Fonte: Autores. 
Para ampliar a compreensão do processo da análise de conteúdo realizada na pesquisa se traz um resumo da Inferência.

A categoria teve a seguinte divisão nas unidades de registro: Discurso institucional projetivo e o discurso institucional real.

Na primeira unidade, há o discurso da intenção, onde a organização deseja que seu empregado assimile o comportamento e o pratique no cotidiano; na segunda, há o discurso das atitudes que estavam ocorrendo, dos comportamentos indesejados pela empresa e que entende muito ruim para ela, razão quer que sejam evitados nas ações dos seus funcionários.

Nesta categoria, a unidade de registro discurso institucional projetivo tem o tema: O resultado como valor social. A escolha desse tema e seu agrupamento nessa categoria se deveu a repetição do termo ética em quase todas as mensagens, como também o resultado deveria ser construído com base nesse valor, por inferência se intuiu que o resultado econômico com ética nos negócios é um resultado com valor social e, portanto, sustentável, oferecendo aos clientes efetivamente o que ele quer e à empresa, resultados de longo prazo e fiéis ao momento negocial.

Para a unidade de contexto elementar respectiva, a expressão encontrada foi: Ter ética como valor desejável na geração dos resultados.

Pode se dizer que essa é uma guerra de guerrilha dentro da organização, um desejo de transformação que ocorra sem matar a imagem idílica de perfeição que ecoa das mensagens corporativas no canal de comunicação selecionado.

Em seguida, aparece o discurso institucional real e seu tema: $O$ resultado como valor único.

Esse tema se depreende tanto da observação participante do autor, quanto do estudo de Bedani (2008, p. 258), que demonstra como o tema 0 resultado como valor único estruturou toda a cultura organizacional como ela é hoje.

Embora haja o discurso do resultado sustentável, na prática organizacional, o resultado puro e simples é o que de fato importa, não o meio 
como se foi alcançado.

Para a Categoria a ideologia do resultado sustentável, no tocante ao discurso institucional real e o tema, o resultado como valor único a respectiva unidade de contexto elementar é a seguinte: Sua história é contada pelo resultado.

Esta unidade de contexto elementar está diretamente relacionada a primazia da função econômica como valor maior da cultura organizacional voltada para os resultados, visto que a história profissional do gerente geral de unidade de varejo da instituição financeira é basicamente contada pelos resultados que apresenta em sua trajetória de curso prazo, sendo de fato o que importa, tanto do ponto de vista do gestor, quanto dos decisores para o encarreiramento ou sua interrupção no programa de ascensão profissional da empresa. Na prática profissional, este é o valor único. Todo o restante de valores que a empresa prega é subjacente.

Para fins de exemplificação de uma interpretação mais específica da categoria mencionada, se trouxe o caso onde se identificou a existência de contradições entre as prescrições do discurso institucional projetivo e as prescrições do discurso institucional real.

Tal situação, segundo o referencial teórico consultado, indica que a empresa não quer que os seus empregados tenham consciência de que ocorre, então ela se utilizando de duas táticas de influência exerce poderosa pressão.

A primeira das táticas identificadas é uma das "formas de vigília do imaginário do tipo regras ideologicamente formuladas" (FARIA, 2007), pois por meio dela a empresa busca um "reforço" da tática de domínio ideológico da "autopersuasão" (PAGÈS, 2008), já amplamente empregada, de maneira que o novo discurso oficial seja reforçado na intenção de anular as contradições entre os temas identificados nesta categoria.

\section{Considerações finais}

Este artigo se propôs a apresentar uma visão resumida, mas contendo todas as etapas teóricas da metodologia de pesquisa de comunicação Análise 
de Conteúdo, sob o critério de condução da pesquisa elaborado por Bardin (2010), como também trazer ao leitor uma exemplificação de sua aplicação em uma pesquisa empírica.

A metodologia tem uma complexidade que exige do pesquisador um aprofundamento ou uma imersão tanto no corpus a ser estudado quanto no referencial teórico, visto que lhe servirá de base para as interpretações e para as inferências.

Destaque deve ser colocado para a etapa de categorização, pois vencida essa etapa, a etapa de análise, interpretação e inferência se tornarão mais fáceis e se bem realizadas podem permitir que pesquisa chegue a bom termo.

A pesquisa foi conduzida sem o uso de aplicativos específicos para a análise de conteúdo.

Saliente-se que o método tem elevada complexidade e também exige muito tempo para a sua realização, mas, a par dessa realidade, o método, se bem aplicado, possibilita ao analista e à ciência alta qualidade na pesquisa qualitativa ao permitir a construção de inferências e resultados em pesquisa sobre comunicação com elevado nível de efetividade.

\section{Referências}

AZEVEDO, Francisco Ferreira dos Santos. Dicionário analógico da língua portuguesa: ideias afins/thesaurus. 2. ed. Rio de Janeiro: Lexikon, 2010.

BARDIN, Laurence. Análise de conteúdo. 4. ed. Lisboa: Edições70, 2010.

BEDANI, Marcelo. Valores, práticas e criatividade organizacional: estudo do perfil cultural de uma instituição bancária. 2008. 318 f. Tese (Doutorado) Universidade Nacional de Brasília, Instituto de Psicologia, Brasília, 2008.

Disponível em:

<http://bdtd.bce.unb.br/tedesimplificado/tde_busca/arquivo.php?codArquivo=4 551>. Acesso em: 23 fev. 2015.

BIAGINI, Liane. As ouvidorias públicas nas instituições de ensino superior: a experiência da Universidade Federal de Pernambuco. 2013. Dissertação (Mestrado Profissional em Gestão Pública para o Desenvolvimento do Nordeste) - Universidade Federal de Pernambuco, Recife, 2013. 
CORPUS. In: AULETE Digital. Disponível em:

<http://www.aulete.com.br/corpus>. Acesso em: 15 ago. 2016.

ENRIQUEZ, E. A organização em análise. Petrópolis: Vozes, 1997.

FARIA, José Henrique (Org.). Análise crítica das teorias e práticas organizacionais. São Paulo: Atlas, 2007.

GRAY, David. E. Pesquisa no mundo real. 2. ed. Porto Alegre: Penso, 2012.

MARCHIORI, Marlene. Os desafios da comunicação interna nas organizações. Conexão: Comunicação e Cultura, Caxias do Sul, v. 9, jan./jun, 2010. Disponível em: <http://www.ucs.br/etc/revistas/index.php/conexao/article/view/466>. Acesso em: 20 dez. 2014.

MOZZATO, Anelise Rebelato; GRZYBOVSKI, Denize. Análise de conteúdo como técnica de análise de dados qualitativos no campo da administração: potencial e desafios. Revista de Administração Contemporânea, Curitiba, v. 15, n. 4, p. 731-747, jul./ago. 2011. Disponível em: <http://www.scielo.br/pdf/rac/ v15n4/a10v15n4.pdf>. Acesso em: 30 jan. 2015.

PAGÈS, Max et al. O poder das organizações. Tradução de Maria Cecília Pereira Tavares. São Paulo: Atlas, 2008.

ROCHA, Francisco Eduardo de Castro et al. Aplicação da análise de conteúdo na perspectiva de Bardin em uma aproximação avaliativa do Pronaf - PB. Boletim de Pesquisa e Desenvolvimento, Planaltina, n. 201, mar. 2008. Disponível em: <www.cpac.embrapa.br/download/1251/t > Acesso em: 13 dez. 2014.

SELLTIZ, Claire et al. Métodos de pesquisa nas relações sociais. São Paulo: Universidade de São Paulo, 1975.

VERGARA, Sylvia Constant. Projetos e relatórios de pesquisa em administração. 9. ed. São Paulo: Atlas, 2007. 